\title{
Detection of human papillomavirus-16 in ovarian malignancy
}

\author{
Q-J Wu', M Guo', Z-M Lu', T Li', H-Z Qiao' and Y Ke ${ }^{*, 2}$ \\ 'Inner Mongolia Medical College, Hohehot Municipality O 10000, China; 'Laboratory of Genetics, Beijing Institute for Cancer Research, School of \\ Oncology, Peking University, No.I Da-Hong-Luo-Chang St. West District, Beijing 100034, China
}

\begin{abstract}
Human papillomavirus is the causal factor for cervical cancer. However, the role of HPV infection in ovarian cancer is unclear. This study aimed to determine the presence of human papillomavirus-16 (HPV-16) in ovarian cancer tissues. Archived human ovarian cancer tissues ( $N=54$ cases, 50 are epithelial cancer, four are nonepithelial cancer) embedded in paraffin blocks were used. Controls are 30 nonmalignant ovarian tissue blocks. In situ hybridisation $(\mathrm{ISH})$ and immunohistochemistry $(\mathrm{IHC})$ were used to detect the presence of HPV-I6 and p53 expression. In all, 52 or 36\% of the epithelial ovarian tumours detected by ISH or IHC, respectively, were HPV-I6 E6 positive. In contrast, only $6.7 \%$ of normal ovarian tissues were HPV-I6 positive proved by ISH. Human papillomavirus- 16 infection was significantly higher in cancer tissues compared to controls with an odds ratio of I6.7 (95\% confidence interval $[\mathrm{Cl}]=3.2-7 \mathrm{I} .4, \mathrm{P}<0.0 \mathrm{I})$. No significant correlation between HPV- 16 infection and histological types of cancer was found $(P>0.05)$. p53 gene expression was detected in 42\% epithelial ovarian cancers. No correlation between p53 expression and HPV-I6 infection was found. The results showed the presence of HPV-I 6 E6 in ovarian carcinoma, suggesting that HPV infection might play a role in ovarian carcinogenesis.
\end{abstract}

British Journal of Cancer (2003) 89, 672-675. doi:I0.1038/sj.bjc.660II72 www.bjcancer.com

(c) 2003 Cancer Research UK

Keywords: human papillomavirus-16; p53 tumour suppressor gene; ovarian malignancy

Human papillomavirus (HPV) infection has been identified as the necessary cause of cervical cancer (Bosch et al, 2002). The progression of proliferative epithelial cells at different body sites to carcinoma may also be associated with the high-risk type HPV infection (zur Hausen, 1999). Ovarian tumour is a common neoplasm of the female genital tract and one of the most lethal gynaecologic malignancies (Prazzini et al, 1997). The aetiology of ovarian cancer remains unclear (Boyle et al, 2000). Malignancy of epithelial origin accounts for $85-90 \%$ of the total ovarian tumour morbidity. Therefore, the involvement of HPV infection in epithelial ovarian cancer has been an interesting issue. However, previous studies in different laboratories provided highly controversial results (Kaufman et al, 1987; Leake et al, 1989; Beckmann et al, 1991; Lai et al, 1992, 1994; Duggan et al, 1995; Runnebaum et al, 1995; Sworn et al, 1995; Trottier et al, 1995; Anwar et al, 1996; Kedzia et al, 1996; Mai et al, 1996; Zimna et al, 1997; Manolitsas et al, 1998; Anttila et al, 1999; Chen et al, 1999; Ip et al, 2002). We report here that HPV-16 was found in a series of histologically characterised epithelial ovarian carcinomas from Chinese women.

The oncogenic HPV product E6 targets p53 for degradation and therefore manipulates the host intracellular signal network in cervical cancers (Werness et al, 1990). Less study has been reported about p53 mutation and its relationship with HPV infection in ovarian cancer.

*Correspondence: Dr Y Ke; E-mail: keyang@mx.cei.gov.cn

The study was performed at Laboratory of Genetics, Beijing Institute for Cancer Research, School of Oncology, Peking University, Beijing, China Received 31 January 2003; revised 28 April 2003; accepted 5 June 2003

\section{MATERIALS AND METHODS}

\section{Source and histological type of specimens}

The patient group consisted of 50 epithelial ovarian carcinomas and four nonepithelial ovarian carcinomas. The mean age of the patients was 47 years (range 27-71 years). Histological types for 50 epithelial cancers were 24 serous cystadenocarcinomas, 19 mucinous cystadenocarcinomas, five endometrioid adenocarcinomas, and two undifferentiated carcinomas. Histological types for four nonepithelial cancers were two thecomas, one endodermal sinus tumour, and one malignant mesothelioma. The control group consisted of 30 pathologically confirmed nonmalignant ovarian tissues collected from 30 women (mean age 53 years; range 27-62 years). Among the nonmalignant tissues, 24 were ovaries removed for uterine pathology, five were ovarian cysts, and one was polycystic ovarian syndrome. Specimens were paraffinembedded and archived from 1996-2000 in Inner Mongolia Medical College affiliated hospital.

Sections of $5 \mu \mathrm{m}$ thickness were cut from formalin-fixed, paraffin-embedded blocks. Tissue sections were attached on APES-treated glass slides for in situ hybridisation (ISH) and immunohistochemistry (IHC).

\section{In situ hybridisation}

The full-length HPV-16 E6 gene was kindly provided by Dr zur Hausen. A 483 bp E6 probe was labelled with digoxin using an in vitro transcription kit (Boehringer Mannheim, Rocha Diagnostic $\mathrm{GmbH}$, Agency Organisation GD-M Sandhoferstr-116, D-68305 Mannheim, Germany). Briefly, the in vitro transcription vector 
containing E6 gene was linearised by SalI digestion. The transcription was performed with T7 RNA polymerase in the presence of digoxin-labelled UTP and other unlabelled NTPs.

The paraffin sections were dewaxed, rehydrated and treated with $0.1 \mathrm{~N} \mathrm{HCl}$. The tissue slides were then digested with proteinase $\mathrm{K}$ at $37^{\circ} \mathrm{C}$ for $15 \mathrm{~min}$. The HPV-16 E6 probe was mixed with hybridisation solution containing $50 \%$ formamide, $4 \times$ SSC, $5 \%$ dextran sulphate, $5 \times$ Denhardt's solution and $200 \mathrm{mg} \mathrm{ml}^{-1} \mathrm{ssDNA}$. The tissue slides were incubated overnight at $42^{\circ} \mathrm{C}$ in $20 \mu \mathrm{l}$ of the hybridisation solution with probe. The slides were washed in SSC. The E6 hybrid was detected by an alkaline phosphatase-conjugated antidigoxin antibody. The tissue slides were observed under a microscope. Pictures were taken for analyses. The HPV-16-positive oesophageal cancer was used as positive control (Li et al, 2001). The hybridisation solution without probes has been used as negative control. In situ hybridisation mostly detects the transcripts of a gene. The antisense probe hybridises with mRNA in the test system. Therefore, sense probe is a desired negative control. However, E6 integration in the host genome might result in transcription in both directions (Higgins et al, 1991; VormwaldDogan et al, 1992). Therefore, blank hybridisation was used as the control in this report.

\section{Immunohistochemistry}

Specimens were dewaxed and treated with PBS containing 3\% hydrogen dioxide. Slides were incubated at $37^{\circ} \mathrm{C}$ in normal goat serum for $15 \mathrm{~min}$ to eliminate nonspecific binding. Samples were incubated with either anti-HPV-16 E6 antibody (Santa Cruz Biotechnology, 2145 Delaware Ave., Santa Cruz, CA 95060, USA, $1: 100$ dilution) or anti-p53 antibody (Santa Cruz Biotechnology, 1:100 dilution) at $4{ }^{\circ} \mathrm{C}$ overnight. The biotinylated secondary antibody and HRP-labelled streptavidin were then added and incubated at $37^{\circ} \mathrm{C}$ for $30 \mathrm{~min}$. The signal was developed in $\mathrm{DAB}-$ $\mathrm{H}_{2} \mathrm{O}_{2}$ solution. The slides were counterstained with haemotoxylin.

\section{Statistical analysis}

Statistical analysis was performed using $\chi^{2}$ test and odds ratio was used to determine prevalence of HPV-16 infection in epithelial ovarian cancers, nonepithelial ovarian cancers, and normal ovarian tissues.

\section{RESULTS}

In 50 epithelial ovarian cancers, 26 were HPV-16 E6 positive determined by ISH. The positive rate is $52 \%$. Only two or $6.7 \%$ of the normal ovarian tissue samples showed HPV-16 positive using ISH (Table $1, P<0.01$ OR $=16.795 \%$ CI $\sim 3.2-71.4$ ). Human papillomavirus-16 E6 was not detected in any of the nonepithelial ovarian cancers (Table 2). The purple signals represent HPV-16 E6 located mainly in the cytoplasm as described (Vormwald-Dogan et al, 1992) (Figure 1).

Using immunohistochemical stain, 18 or $36 \%$ of the epithelial ovarian cancers were HPV-16 positive. All the positive samples detected by IHC were those positive samples detected by ISH. The brown signal located in the cytoplasm represents E6 protein (Figure 2).

A total of 21 or $42 \%$ of the epithelial ovarian cancers were p53

Table I HPV-16 E6 detection in epithelial ovarian carcinomas and normal ovaries by ISH

\begin{tabular}{lccc}
\hline & Tested case & Positive & Percentage \\
\hline Ovarian carcinoma & 50 & 26 & 52 \\
Normal ovary & 30 & 2 & 6.7 \\
\hline
\end{tabular}

$P<0.01 ; \chi^{2}$ test; $\mathrm{OR}=16.7,95 \% \mathrm{Cl}(3.2-7 \mid .4)$.
Table 2 HPV-16 E6 detection in different histological types of ovarian carcinoma

\begin{tabular}{|c|c|c|c|c|c|}
\hline \multirow[b]{2}{*}{ Histological types } & \multirow[b]{2}{*}{$\mathbf{N}$} & \multicolumn{2}{|c|}{ ISH } & \multicolumn{2}{|c|}{ IHC } \\
\hline & & $n$ & $\%$ & $n$ & $\%$ \\
\hline Serous cystadenocarcinoma & 24 & 15 & $62.5 \mathrm{a}$ & 10 & $41.7^{b}$ \\
\hline Mucinous cystadenocarcinoma & 19 & 8 & 47.4 & 5 & 26.3 \\
\hline Endometrioid adenocarcinoma & 5 & 2 & & 2 & \\
\hline Undifferentiated carcinoma & 2 & I & & I & \\
\hline Thecomas tumour ${ }^{c}$ & 2 & 0 & & 0 & \\
\hline Endodermal tumour ${ }^{c}$ & । & 0 & & 0 & \\
\hline Malignant mesothelioma ${ }^{c}$ & 1 & 0 & & 0 & \\
\hline
\end{tabular}

${ }^{\mathrm{a}} P>0.05 ; \chi^{2}$ test; ${ }^{\mathrm{b}} P>0.05 ; \chi^{2}$ test. ${ }^{\mathrm{c}}$ Nonepithelial ovarian carcinomas.
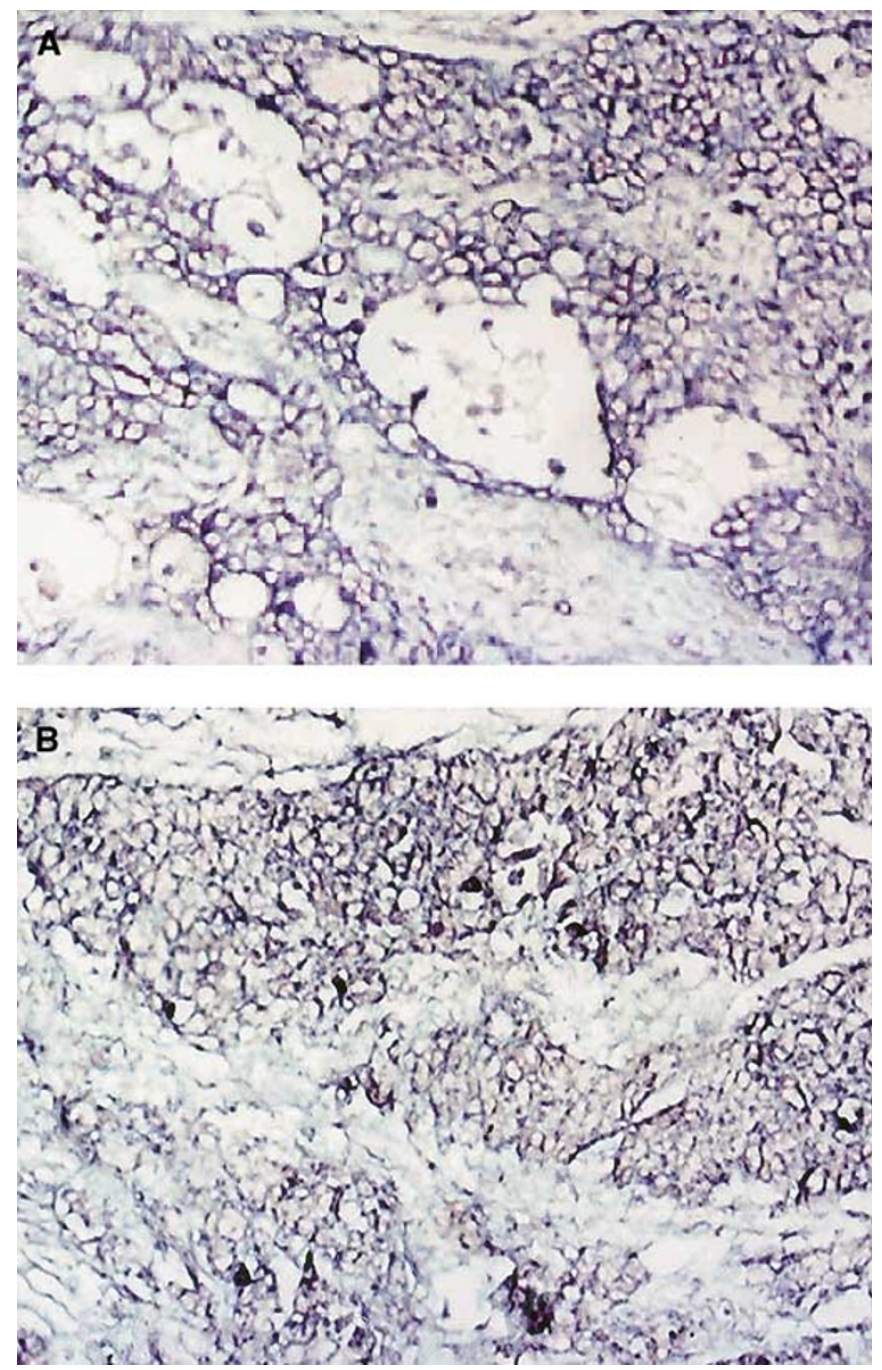

Figure I HPV-I6 E6 in ovarian cancers by ISH, (A) sample no. 990917 and (B) sample no. 990193. The purple blue signals representing the expression of the E6 mRNA are at cytoplasm in the tumour cells. ( $\mathbf{A}, \mathbf{B}$ : original magnification $\times 100$ )

positive. The brown signal located uniquely within the nucleus represents p53 protein. No correlation has been found between HPV-16 infection and p53 positive (Table $3, P>0.05$ ).

HPV-16 infection was not identified in any nonepithelial ovarian cancers, which are not the primary host for HPV. There was no correlation between HPV infection and histological types of 

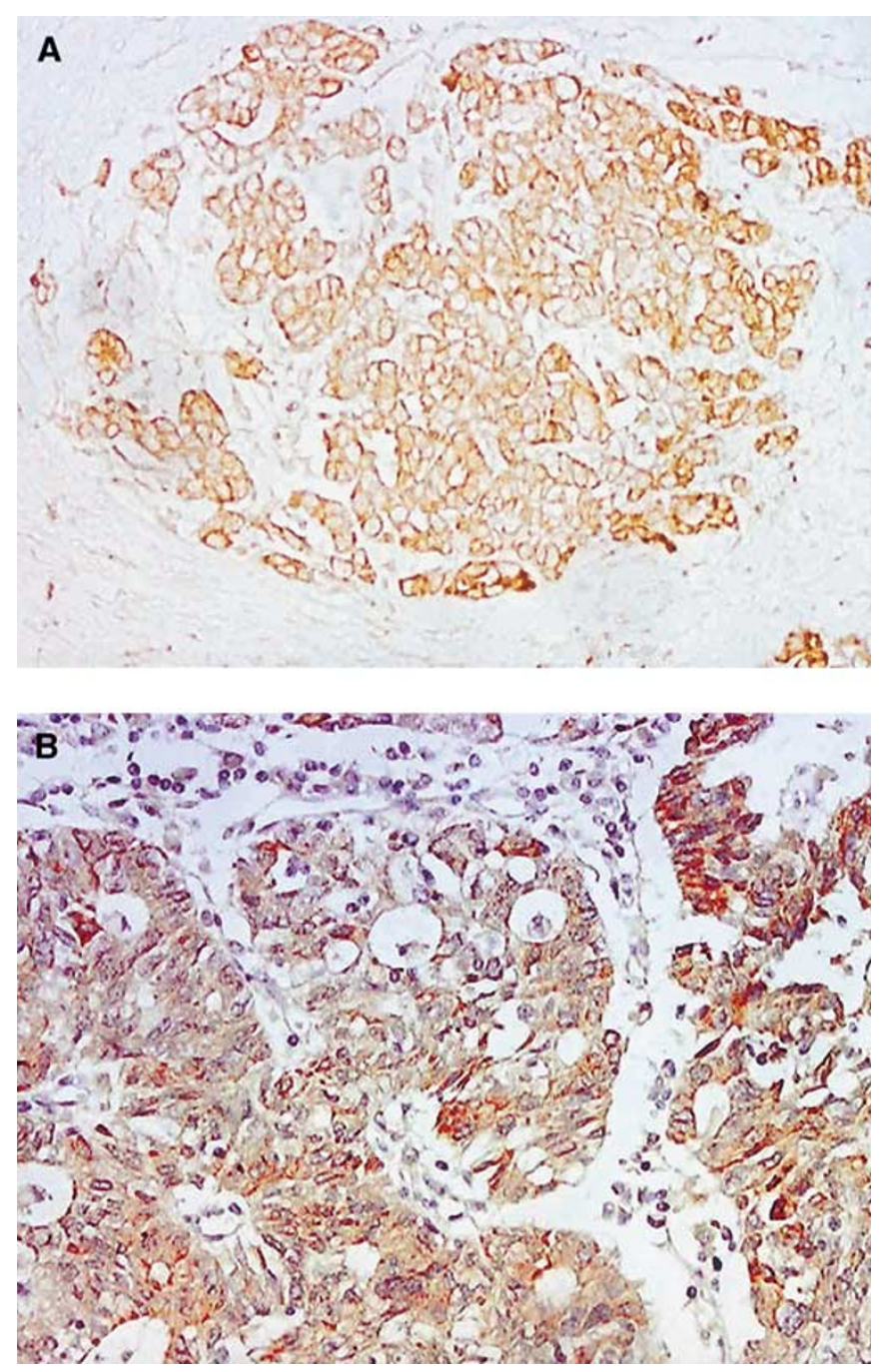

Figure 2 HPV-I6 E6 in ovarian cancers by IHC, (A) sample No. 990917 and (B) sample no. 990589. The brown signals representing the expression of the E6 protein are mainly at cytoplasm in the tumour cells. (A, B: original magnification $\times 100$ ).

Table 3 Correlation between HPV-I6 E6 infection and p53 mutation

\begin{tabular}{lcc}
\hline & \multicolumn{3}{c}{ HPV-16 } \\
\hline p53 & Positive & Negative \\
Positive & 14 & 7 \\
Negative & 12 & 17 \\
\hline
\end{tabular}

$P>0.05 ; \chi^{2}$ test.

ovarian cancers (Table 2, $P>0.05$ ). Owing to the sample size limitation, statistical comparison was only carried out between cystadenocarcinomas and mucinous cystadenocarcinomas.

\section{DISCUSSION}

Human papillomaviruses play a causal role in cervical cancer. Human papillomavirus infection is also detected in other cancers of the female lower genital tract, including cancers of vulva, vagina, and perineum (Gupta et al, 1987; Shah et al, 1996; Dillner et al, 1997). However, the role of HPV infection in the development of cancers in the upper genital tract, such as endometrial cancer and ovarian cancer, is less clear. The first report on HPV infection in ovarian cancers was published in 1987 (Kaufman et al, 1987), although the article was retacted 1 year later by the authors. To date about 16 additional reports on HPV infection in ovarian tumours were found in the MEDLINE. Among these, 10 analysed more than 10 tumour specimens in each report (Leake et al, 1989; Beckmann et al, 1991; Lai et al, 1992, 1994; Runnebaum et al, 1995; Trottier et al, 1995; Zimna et al, 1997; Anttila et al, 1999; Chen et al, 1999; Ip et al, 2002). Only in four of the 10 studies, HPV infection was found in ovarian cancers (Lai et al, 1992, 1994; Zimna et al, 1997; Ip et al, 2002). It is interesting that in three of the positive reports, specimens of Chinese origin were used (Lai et al, 1992, 1994; Ip et al, 2002). In the present study, a total of 54 ovarian cancers and 30 nontumour ovarian specimens were analysed for the presence of HPV-16. Among the 50 epithelial ovarian cancers, a total of $26(52 \%) \mathrm{HPV}-16$ positive were found. Our results are consistent with those reports based on Chinese origin specimens. These independent studies are from three areas of grand China, Mainland China, Taiwan, and Hong Kong, suggesting that host genetic makeup may play an important role in susceptibility to HPV infection. Alternatively, HPV intratypic variants in different geographical regions may also determine the association with the risk of ovarian cancer. It has been reported that the distribution of HPV variants varied in different geographical areas, suggesting that the virus and the host have coevolved over time (Ho et al, 1993; Ong et al, 1993; Heinzel et al, 1995; Stewart et al, 1996; Yamada et al, 1995, 1997; Hildesheim et al, 2002). Epidemiology studies in cervical cancers showed that individuals infected with a non-European variant of HPV-16 were associated with 2-9- fold increased risk of cervical cancer (Hildesheim et al, 2002). Whether this is the case in ovarian cancer needs to be further investigated.

In addition to the host and pathogen genetic variation, the difference of the detection methods employed in the studies might also account for data discrepancy. It has been well documented in cervical cancer that the episomal viral DNA frequently integrates into the host genome as HPV-infected lesions progress to cervical cancer. During viral DNA integration, only E6 and E7 genes remained (zur Hausen, 2002) in the host genome. Therefore, the presence of E6 or E7 genes in tumour tissues may better represent the real HPV infection. In some studies, L1 was used as the only indicator, which may have been lost or not expressed in the malignant specimens. We suggest that a well recognised standard for HPV detection in tumours should be issued for further studies.

In this study, we employed both ISH and IHC to detect HPV-16 E6 expression. Among the $26 \mathrm{HPV}-16$-positive cancer samples detected by ISH, 18 were confirmed positive by IHC. More importantly, none of ISH-negative samples were detected positive by IHC. These results indicate that IHC is an accurate method with less sensitivity.

The prevalence of HPV-16 infection in ovarian cancers is much higher than in nonmalignant ovarian tissues, suggesting that HVP16 infection may play a role in the development of ovarian cancer. However, large case-control studies need to be conducted before reaching a conclusion.

Mutations of p53 are frequently detected in ovarian cancer (Crook et al, 1992; Kmet et al, 2003). Consistent with those studies, we found that $42 \%$ of ovarian cancers were p53 positive. The expression of p53 was not correlated with HPV infection. It has been proposed that the mechanism for the loss of $\mathrm{p} 53$ function in cervical cancer is due to degradation by HPV E6. Therefore, p53 mutation is rare in cervical cancers. However, there are reports suggesting that the association between HPV infection and p53 mutation differs among tumours (Hachisuga et al, 1996; Hasegawa et al, 2002), suggesting that additional mechanisms may be involved in tumorigenesis of other origins. 


\section{REFERENCES}

Anttila M, Syrjanen S, Ji H, Saarikoski S, Syrjanen K (1999) Failure to demonstrate human papillomavirus DNA in epithelial ovarian cancer by general primer PCR. Gynecol Oncol 72: 337-341

Anwar K, Nakakuki K, Imai H, Shiraishi T, Inuzuka M (1996) Infection of human papillomavirus (HPV) and p53 over-expression in human female genital tract carcinoma. J Pak Med Assoc 46: 220-224

Beckmann AM, Sherman KJ, Saran L, Weiss NS (1991) Genital-type human papillomavirus infection is not associated with surface epithelial ovarian carcinoma. Gynecol Oncol 43: $247-251$

Bosch FX, Lorincz A, Munoz N, Meijer CJLM, Shah KV (2002) The causal relation between human papillomavirus and cervical cancer. J Clin Pathol 55: $244-265$

Boyle P, Maisonneuve P, Autier P (2000) Update on cancer control in women. Int J Gynecol Obstet 70: 263-303

Chen TR, Chan PJ, Seraj IM, King A (1999) Absence of human papillomavirus E6-E7 transforming genes from HPV 16 and 18 in malignant ovarian carcinoma. Gynecol Oncol 72: $180-182$

Crook T, Wrede D, Tidy JA, Mason WP, Evans DJ, Vousden KH (1992) Clonal p53 mutation in primary cervical cancer: association with humanpapillomavirus-negative tumours. Lancet 339: 1070-1073

Dillner J, Lehtinen M, Bjorge T, Luostarinen T, Youngman L, Jellum E, Koskela P, Gislefoss RE, Hallmans G, Paavonen J, Sapp M, Schiller JT, Hakulinen T, Thoresen S, Hakama M (1997) Prospective seroepidemiologic study of human papillomavirus infection as a risk factor for invasive cervical cancer. J Natl Cancer Inst 89: 1293-1299

Duggan MA, Rowlands C, Kneafsey PD, Nation JG, Stuart GC (1995) Uterine atypical polypoid adenomyoma and ovarian endometrioid carcinoma: metastatic disease or dual primaries? Int J Gynecol Pathol 14: 81 - 86

Gupta J, Pilotti S, Rilke F, Shah K (1987) Association of human papillomaviruse type 16 with neoplastic lesions of the vulva and other genital sites by in situ hybridization. Am J Pathol 127: 206-215

Hachisuga T, Matsuo N, Iwasaka T, Sugimori H, Tsuneyoshi M (1996) Human papilloma virus and p53 overexpression in carcinomas of uterine cervix, lower uterine segment and endometrium. Pathology 28: 28-31

Hasegawa M, Ohoka I, Yamazaki K, Hanami K, Sugano I, Nagao T, Asoh A, Wada N, Nagao K, Ishida Y (2002) Expression of p21/WAF-1, status of apoptosis and p53 mutation in esophageal squamous cell carcinoma with HPV infection. Pathol Int 52: $442-450$

Heinzel PA, Chan SY, Ho L, O'Connor M, Balaram P, Campo MS, Fujinaga K, Kiviat N, Kuypers J, Pfister H (1995) Variation of human papillomavirus type 6 (HPV-6) and HPV-11 genomes sampled throughout the world. I Clin Microbiol 33: 1746-1754

Higgins GD, Uzelin DM, Phillips GE, Burrell CJ (1991) Presence and distribution of human papillomavirus sense and antisense RNA transcripts in genital cancer. J Gen Virol 72: 885-895

Hildesheim A, Wang SS (2002) Host and viral genetics and risk of cervical cancer. Virus Res 89 (2): $229-240$

Ho L, Chan SY, Burk RD, Das BC, Fujinaga K, Icenogle JP, Khan T, Kiviat N, Lancaster W, Mavromara-Nazos P, Labropoulou V, MitraniRosenbaum S, Norrild B, Pilai MR, Stoerker J, Syrjaene K, Syrjaene S, Tay SK, Villa LL, Wheeler CM, Williamson AL, Bernard HU (1993) The genetic drift of human papillomavirus type 16 is a means of reconstructing prehistoric viral spread and the movement of ancient human populations. J Virol 67: 6413-6423

Ip SM, Wong LC, Xu CM, Cheung AN, Tsang PC, Ngan HY (2002) Detection of human papillomavirus DNA in malignant lesions from Chinese women with carcinomas of the upper genital tract. Gynecol Oncol 87: 104-111

Kaufman RH, Bornstein J, Gordon AN, Adam E, Kaplan AL, Adler-Storthz K (1987) Detection of human papillomavirus DNA in advanced epithelial ovarian carcinoma. Gynecol Oncol 27: 340-349

Kedzia WM, Gozdzicka-Jozefiak A, Kedzia H (1996) Human papillomavirus type 16 in ovarian serous surface papilloma. Eur J Gynaecol Oncol 17: $354-356$

Kmet LM, Cook LS, Magliocco AM (2003) A review of p53 expression and mutation in human benign, low malignant potential, and invasive epithelial ovarian tumors. Cancer 97: 389-404
Lai CH, Hsueh S, Lin CY, Huang MY, You GB, Chang HC, Pao CC (1992) Human papillomavirus in benign and malignant ovarian and endometrial tissues. Int J Gynecol Pathol 11: 210-215

Lai CH, Wang CY, Lin CY, Pao CC (1994) Detection of human papillomavirus RNA in ovarian and endometrial carcinomas by reverse transcription/polymerase chain reaction. Gynecol Obstet Invest 38: $276-280$

Leake JF, Woodruff JD, Searle C, Daniel R, Shah KV, Currie JL (1989) Human papillomavirus and epithelial ovarian neoplasia. Gynecol Oncol 34: $268-273$

Li T, Lu ZM, Chen KN, Guo M, Xing HP, Mei Q, Yang HH, Lechner JF, Ke Y (2001) Human papillomavirus type 16 is an important infectious factor in the high incidence of esophageal cancer in Anyang area of China. Carcinogenesis 22: $929-934$

Mai KT, Yazdi HM, Bertrand MA, LeSaux N, Cathcart L (1996) Bilateral primary ovarian squamous cell carcinoma associated with human papilloma virus infection and vulvar and cervical intraepithelial neoplasia: a case report with review of the literature. Am J Surg Pathol 20: $767-772$

Manolitsas TP, Lanham SA, Hitchcock A, Watson RH (1998) Synchronous ovarian and cervical squamous intraepithelial neoplasia: an analysis of HPV status. Gynecol Oncol 70: 428-431

Ong CK, Chan SY, Campo MS, Fujinaga K, Mavromara P, Pfister H, Tay SK, Meulen JT, Villa LL, Bernard HU (1993) Evolution of human papillomavirus type 18: an ancient phylogenetic root in Africa and intratype diversity reflect coevolution with human ethnic groups. J Virol 67: $6424-6431$

Parazzini F, Franceschi S, La Vecchia C, Chatenoud L, Di Cintio E (1997) The epidemiology of the female genital tract cancers. Int J Gynecol Cancer 7: $169-181$

Runnebaum IB, Maier S, Tong XW, Rosenthal HE, Mobus VJ, Kieback DG, Kreienberg R (1995) Human papillomavirus integration is not associated with advanced epithelial ovarian cancer in German patients. Cancer Epidemiol Biomarkers Prev 4: 573-575

Shah KV, Howley PM (1996) Papillomaviruses. In: Fields BN, Knipe DM, Howley PM, (eds) Fields Virology, Vol. 2, pp 2077-2109. Philadelphia: Lippincott-Raven

Stewart ACM, Eriksson AM, Manos MM, Munoz N, Bosch FX, Peto J, Wheeler CM (1996) Intratype variation in 12 human papillomavirus types: a worldwide perspective. J Virol 70: $3127-3135$

Sworn MJ, Jones H, Letchworth AT, Herrington CS, McGee JO (1995) Squamous intraepithelial neoplasia in an ovarian cyst, cervical intraepithelial neoplasia, and human papillomavirus. Hum Pathol 26: $344-347$

Trottier A-M, Provencher D, Mes-Masson A-M, Vauclair R, Coutlee F (1995) Absence of human papillomavirus sequences in ovarian pathologies. J Clin Microbiol 33: 1011 - 1013

Vormwald-Dogan V, Fischer B, Bludau H, Freese UK, Gissmann L, Glitz D (1992) Sense and antisense transcripts of human papillomavirus type 16 in cervical cancer. J Gen Virol 73: $1833-1838$

Werness BA, Levine AJ, Howley PM (1990) The E6 proteins encoded by HPV-16 and 18 can complex p53 in vitro. Science 248: 76-79

Yamada T, Wheeler CM, Halpern AL, Stewart ACM, Hildesheim A, Jenison SA (1995) Human papillomavirus type 16 variant lineages in United States populations characterized by nucleotide sequence analysis of the E6, L2, and L1 coding segments. J Virol 69: $7743-7753$

Yamada T, Manos M, Peto J, Greer CE, Munoz N, Bosch FX, Wheeler CM (1997) Human papillomavirus type 16 sequence variation in cervical cancers: a worldwide perspective. J Virol 71: $2463-2472$

Zimna K, Poreba E, Kedzia W, Gozdzicka-Jozefiak A, Kedzia H (1997) Human papillomavirus (HPV) in upper genital tract carcinomas of women. Eur J Gynaecol Oncol 18: $415-417$

zur Hausen H (1999) Papillomaviruses in human cancers. Proc Assoc Am Phys 111: $1-7$

zur Hausen $\mathrm{H}$ (2002) Papillomavirus and cancer: from basic studies to clinical application. Nat Rev Cancer 2: 342-350 